\title{
"Un pareado - la mano del tiempo", sobre la expresión emocional del mundo nostálgico entre oriente y occidente
}

\author{
Kun Xiu ${ }^{1}$; Gema Hoyas ${ }^{2}$ \\ ${ }^{1}$ China, Doctorando en la Universitat Politécnica de València, kun.xiu@hotmail.com \\ ${ }^{2}$ Spain, PDI Universitat Politécnica de València, gehofro@esc.upv.es
}

\begin{abstract}
Our project is the search for the lyrical expression of images about time and nostalgia from the intercultural perspective of the East and West. In the context of the current era of big data, the trend towards the integrated development of traditional and new media is increasingly evident. However, how to use the media resources and information that we have to understand and communicate the meaning of the image according to different cultures, remains worthy of reflection.
\end{abstract}

Time is like an invisible hand, pushing everything forward... The rhythm of movements, the subtle landscape and the simplest actions are intertwined and connected.

This video project explores the timeless theme of time and nostalgia. Through the use of different simultaneous perspectives, with the resource of the double screen and the hybridization of media, we obtain a flow of images where the dynamic and apparently static are intertwined with the aim of highlighting the nostalgic element as a way of distinguishing between different cultures and their unique expressions, in order to build cultural identity. For this, the project starts from two parallel vertical images, which advance independently, while remaining related to each other. This piece searches for the lyrical intersection in the rhythm of things and people, showing the traces of time; uses the cognition of nostalgia for Eastern and Western cultures, and their particular expressions, to lead to the encounter of cultural identity. This can give us a deeper understanding and empathy of the visual language of Eastern and Western cultures, while also showing more creative possibilities from a multicultural landscape.

Keywords: Nostalgia, time, lyrical expression, cultural identity, interculturality 
"Un pareado - la mano del tiempo", sobre la expresión emocional del mundo nostálgico entre oriente y occidente

\section{Resumen}

Nuestro proyecto es la búsqueda de la expresión lírica de imágenes sobre el tiempo y la nostalgia desde la perspectiva intercultural oriente y occidente. En el contexto de la era actual de los macrodatos, la tendencia al desarrollo integrado de los medios tradicionales y los nuevos medios es cada vez más evidente. Sin embargo, cómo utilizar los recursos mediáticos y la información que tenemos para comprender y comunicar el significado de la imagen según las diferentes culturas, sigue siendo motivo digno de reflexión.

El tiempo es como una mano invisible, empujando todo hacia adelante... El ritmo de los movimientos, el paisaje sutil y las acciones más simples están entrelazadas y conectadas.

Este proyecto de vídeo explora una temática atemporal, la del tiempo y la nostalgia. Mediante el empleo de distintas perspectivas simultáneas, con el recurso de la doble plantalla y la hibridación de medios, obtenemos un flujo de imágenes donde lo dinámico y aparentemente estático se entrelazan con el objetivo de resaltar el elemento nostálgico como vía de distinción entre diferentes culturas y sus expresiones únicas, con el fin de construir la identidad cultural. Para ello el proyecto parte de dos de imágenes verticales paralelas, las cuales avanzan de forma independiente, manteniéndose al mismo tiempo relacionadas entre sí. Esta pieza realiza una búsqueda de la intersección lírica en el ritmo de las cosas y las personas, mostrando las huellas del tiempo; utiliza la cognición de la nostalgia de las culturas de oriente y occidente, y sus expresiones particulares, para llevar al encuentro de la identidad cultural. Esto puede brindarnos una comprensión y empatía más profundas del lenguaje visual de las culturas oriental y occidental, al mismo tiempo que mostrará más posibilidades creativas desde un panorama multicultural.

Palabras clave: Nostalgia, tiempo, expresión lírica, identidad cultural, interculturalidad

\section{Introducción}

En el contexto de la era actual de los macrodatos, la tendencia al desarrollo integrado de los medios tradicionales y los nuevos medios es cada vez más evidente. Sin embargo, cómo utilizar los recursos y la información que tenemos para comprender y comunicar el significado de la imagen según las diferentes culturas, sigue siendo motivo digno de reflexión. Con esta motivación se creó la obra audiovisual "Un pareado - la mano del tiempo" de la que deriva el presente texto. Nos planteamos la búsqueda de la 
Kun Xiu, Gema Hoyas

expresión lírica de imágenes sobre el tiempo y la nostalgia, apelando al recuerdo y la naturaleza, desde la perspectiva intercultural oriente y occidente.

\section{Contenido}

\subsection{El tiempo}

Iniciamos este texto con la afirmación de que el tiempo es como una mano invisible, empujando todo hacia adelante... El arte lo ha reflejado en imágenes, el tiempo ha sido un tema atemporal que ha atravesado épocas y culturas y que ha tenido su reflejo en la obra de muchos artistas. Como ejemplos más evidentes la obra de los artistas orientales del estilo Shan shui que expresan sus sentimientos y emociones a través del paisaje natural, o del movimiento romántico del siglo XXIII en occidente que introdujo la estética de las ruinas y la nostalgia en la visión del público, y comenzó a enfocarse en usar emociones fuertes como fuente de experiencia estética.

También en la obra de artistas más contemporáneos, como la de Bill Viola y la de Nobuhiro Nakanishi en las que podemos encontrar reflexiones muy poéticas relacionadas con el tiempo. En la obra Inverted Birth (2014) de Bill Viola, el artista utiliza el ritmo extremadamente lento de las imágenes de video para crear un sentido del tiempo vivido, experienciado, y presenta y expresa etapas importantes de la vida mediante el uso de elementos como tierra, sangre, leche, agua y aire. En la instalación fotográfica visual Layer Drawings (2012) del artista japonés Nobuhiro Nakanishi, Nobuhiro creó la sensación del paso del tiempo al fotografiar el mismo objeto en diferentes momentos e imprimirlo en un soporte de vidrio ordenando la serie de imágenes de forma que crean una sutil diferencia, solo apreciable para la contemplación pausada. Los recursos estéticos que cada artista recoge en su trabajo van de la mano del contexto histórico y social en el que se sitúan.

Así mismo la nostalgia, como un sentimiento hacia el paso del tiempo, es también un tema indispensable en el campo de la creación de imágenes. La nostalgia, como término científico, se hizo común a finales del siglo XVII, propuesto por primera vez en occidente por el suizo Johaness Hofer. La palabra "nostalgia" tiene su origen en las

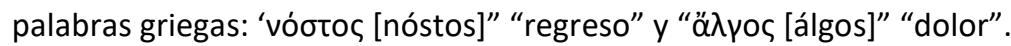

Para Hofer "volver a casa" y "estado de sufrimiento", ya que sus pacientes, soldados, sufrían ese estado de "nostalgia" que él investigó y cuyo anhelo era el regreso al hogar. Originalmente pues, la "nostalgia" en su acepción como término patológico, incluía depresión e incluso autodestrucción y otras enfermedades emocionales. En el siglo XX, algunos académicos realizaron investigaciones más profundas sobre la nostalgia $y$ comenzaron a distinguir la nostalgia de la "homesickness", creían que la nostalgia no era solo un anhelo por un lugar en el pasado, sino también una inclusión más amplia 
"Un pareado - la mano del tiempo", sobre la expresión emocional del mundo nostálgico entre oriente y occidente

como experiencias vividas en otros tiempos o el deseo de recuperar sentimientos independientemente del tiempo, el espacio y la región.

En otras palabras, podemos concretar que la nostalgia es una actividad mental en la que el cerebro conecta inconscientemente las imágenes, olores, sonidos y otras sensaciones del pasado para intentar que volvamos a experimentarlo; es como una experiencia psicológica, una reconstrucción y forja del pasado, y una experiencia emocional con diferentes expresiones basadas en el entorno personal y la experiencia de diferentes individuos.

\subsection{Los recuerdos}

El cuerpo principal de la nostalgia radica en la retrospectiva y el recuerdo de tiempos y vivencias pasadas. Como escribió Schopenhauer "A ello se debe el que, en especial cuando una necesidad nos angustia más de lo habitual, nos sobrevenga el repentino recuerdo de escenas del pasado y la lejanía como un paraíso perdido. La fantasía evoca solamente lo objetivo, no lo individual-subjetivo;" (Schopenhauer, 2009) se evidencia que la nostalgia es una práctica estética realizada a través del recuerdo. Los recuerdos son la única forma de conectarnos con el tiempo y el espacio pasado. Es por el medio de los recuerdos del pasado que el sujeto nostálgico reorganiza las imágenes fragmentadas de cosas, experiencias o personajes que nos afectan profundamente en la memoria, y proyecta emociones para formar una experiencia estética nostálgica.

Cabe señalar que, en comparación con cuando hacemos una retrospectiva general sobre el tiempo, la nostalgia a menudo conlleva emociones personales más subjetivas; el recuerdo aquí no es solo una copia exacta del tiempo que sucedió en el pasado, sino que además son también las cosas o personas que más nos impresionan después de que el cerebro del sujeto someta sus recuerdos a una selección estética-subjetiva.

\subsection{La expresión de la naturaleza}

La tradición cultural china aboga por la idea de "Armonía entre el hombre y la naturaleza". Muchos literatos y artistas desde la antigüedad han estado obsesionados con regresar al idílico paisaje natural. Las emociones que transmite el paisaje natural a veces están más allá de las palabras. Como todos sabemos, el mundo en el que vivimos no es solo un mundo físico, sino también un mundo vivo, un mundo significativo. El poeta y literato chino Tao Yuanming tiene dos frases famosas: "Aquí está la esencia de la vida ermitaña, pero está más allá de mis palabras” “此中有真意, 欲辩已忘言” (Yuanming, 2019, traducción propia), queriendo decir que el mundo en que vivimos es un mundo significativo. El arte, es para encontrar, descubrir y experimentar este significado en la vida. El teórico y poeta chino Yan Yu de la dinastía Song escribió en su libro Canglang Shihua (Yu, 2019, traducción propia): 
Kun Xiu, Gema Hoyas

“Como el sonido del cielo, el color en la pintura,

la luna en el agua, la imagen en el espejo, las palabras tienen un fin, el significado es interminable".

Es precisamente por el rico significado del paisaje, que el uso de escenas naturales para describir sentimientos es una expresión importante del arte chino y el principal medio para expresar la belleza de la concepción artística. Expresar sentimientos a través de escenarios naturales tiene una doble estructura en la conciencia estética: uno es la reproducción artística de las cosas objetivas, el otro es la expresión del espíritu subjetivo, y la conexión orgánica entre los dos, constituye la belleza de la concepción artística de la pintura tradicional china. Por ejemplo, los antiguos artistas chinos solían usar algunas formas naturales de plantas para simbolizar el carácter humano: las flores del loto salen del barro sin mancharse, la flor del ciruelo se alza orgullosamente en el viento frío y la nieve, también la rectitud e integridad moral del bambú... etc. Los artistas representan sus emociones en la escena, y las obras terminadas tocarán las emociones internas del espectador. Es la unidad altamente integrada de emociones internas y escenas naturales. En resumen, también podemos entender el uso de escenarios naturales en la creación artística como la creación natural de una atmósfera.

Además, no es difícil entender que la nostalgia sea hoy en día una reacción estresante, la gente moderna no sabe cómo enfrentar la sociedad extremadamente cambiante. Volver a la naturaleza es también nuestro profundo anhelo.

\subsection{Un pareado - la mano del tiempo}

Esta obra es una búsqueda de la expresión lirica de imágenes sobre el tiempo y la nostalgia desde la perspectiva intercultural oriente y occidente. Mediante el empleo de distintas perspectivas simultáneas, con el recurso de la doble pantalla y la hibridación de medios (fotografía y vídeo), obtenemos un flujo de imágenes donde lo dinámico y lo aparentemente estático se entrelazan con el objetivo de resaltar el elemento nostálgico como vía de distinción entre diferentes culturas y sus expresiones únicas, con el fin de construir la identidad cultural de ambas.

Para ello el proyecto parte de dos de imágenes verticales paralelas, las cuales avanzan de forma independiente, manteniéndose al mismo tiempo relacionadas entre sí. Esta pieza realiza una búsqueda de la intersección lírica en el ritmo de las cosas y las personas, mostrando las huellas del tiempo; utiliza la cognición de la nostalgia de las culturas de oriente y occidente, y sus expresiones particulares, para llevar al encuentro de la identidad cultural.

Por un lado, la emoción nostálgica se construye a través de la conformación de recuerdos por los objetos que aparecen en las imágenes. La asombrosa anciana 
comienza su día fluyendo con los recuerdos, tocando el tiempo con la mano llena de las huellas de los años, las viejas imágenes y las cosas antiguas se llenan de vivencias pasadas que ahora rebrotan a un presente desde el que las contempla. Anduvo por el bosque de los años y sigue caminando tranquilamente hacia el mar del tiempo infinito. Hemos aplicado la característica estética tradicional japonesa de "Mono no aware" es partir de las emociones más naturales de las personas, se requiere que el sujeto mantenga una emoción simple e introvertida hacia las cosas externas, con una actitud solidaria y tolerante hacia todo, para percibir la verdadera belleza de las cosas.

Por otro lado, la mano invisible del tiempo también mueve todo en el mundo. A través de la conformación de la superficie ondulante del agua, reflejos, nubes, brisa, desde amanecer hacia el atardecer, como un suspiro a través de las imágenes del paisaje, cómo pasa el tiempo en silencio. Las dos pantallas se despliegan y funcionan de forma independiente, pero están conectadas entre sí. El ritmo de los movimientos, el paisaje sutil y las acciones más simples están entrelazadas y conectadas. La integración de sentimientos y paisajes no es una simple representación de objetos objetivos ni una combinación aleatoria de ideas subjetivas, sino una unidad de mundos subjetivos y objetivos. Se basa en las imágenes del espacio, a través de la comprensión y la gestión de la imagen del entorno, la intersección de la emoción y la escena, el significado y las imágenes están conectados. Esto también ejemplifica la admiración de la vida natural en la cultura tradicional china: solo a través de la comprensión profunda y la experiencia de la naturaleza objetivamente existente, se puede lograr la integración de los sentimientos y el paisaje. Esto no es solo la base de la creación, sino también la base para apreciar el arte.

\section{Conclusión}

En este proyecto, la imagen se expresa de dos formas para transmitir diferentes presentaciones del paso del tiempo y emociones nostálgicas, para expresar emociones a través de las escenas elegidas, combinando con la forma de expresar recuerdos con los objetos antiguos.

Se utiliza la viveza de las imágenes para crear un efecto visual silencioso pero expresivo y emocional. El color nos acerca a la vivencia del presente que fluye. El uso de la imagen en blanco y negro nos acerca a un sentido de recuerdo y de tiempo suspendido.

Toda esta combinación de formas distintas de expresión puede brindarnos una comprensión y empatía mas profundas del lenguaje visual de las culturas oriental y occidental, al mismo tiempo que mostrará más posibilidades creativas desde un panorama multicultural. 
Kun Xiu, Gema Hoyas

\section{Referencias}

SCHOPENHAUER, A. (2009) El mundo como voluntad y representación Volumen I. Editorial Trotta.

YUANMING, T. (2012). 陶波明诗集. 中州古籍出版社.

YU, Y. (2019) Canglang Shihua: 滄浪詩話. 中国书店出版社. 